\title{
Uma moral "corporal" generificada nos manuais escolares franceses de moral e de higiene (1880-1974)
}

\section{A gendered "corporal" morality in french school textbooks on morality and hygiene (1880-1974)}

\author{
Jacques Gleyse* \\ Avelino Aldo de Lima Neto**
}

\begin{abstract}
RESUMO
O estudo dos manuais escolares franceses de Moral e Higiene do final do século XIX ao segundo terço do século XX permite descrever os preconceitos e estereótipos de gênero ligados aos diversos temas presentes nessas obras. As poucas rupturas nelas identificadas estão mais associadas a mudanças nos procedimentos didáticos do que à questão do gênero. Nesse domínio, 0 tratamento é bastante diferente conforme o sexo. Igualmente distintas são as temáticas encontradas quando se trata do autocuidado, de prescrições e de proibições corporais. Nas recomendações às meninas, são frequentes os assuntos da paciência, do asseio, da temperança, da coragem moral, da ordem, da sobriedade na comida e bebida; nos conselhos aos meninos, surgem as discussões sobre a coragem, a embriaguez, o alcoolismo, as proezas físicas, o suicídio, a mutilação, o trabalho e a preguiça. Os acontecimentos marcantes quanto à situação da mulher no século $\mathrm{XX}$ não parecem ter impactado os manuais escolares, tanto em termos dos textos escolhidos como da iconografia, com pouquíssimas exceções.
\end{abstract}

Palavras-chave: Gênero. Igualdade. Sexo. Moral. Higiene.

*Université de Montpellier. Montpellier, France. E-mail: jacques.gleyse@orange.fr - https:// orcid.org/0000-0002-8459-5958

*** Instituto Federal de Educação, Ciência e Tecnologia do Rio Grande do Norte. Programa de Pós-Graduação em Educação Profissional e em Educação. E-mail: ave.neto@hotmail.com - https:// orcid.org/0000-0003-4810-8742 


\begin{abstract}
The study of French textbooks on Moral and Hygiene, from the end of the 19 th century to the second third of the 20th century, allows us to describe the prejudices and gender stereotypes linked to the various themes present in these works. The few ruptures identified in them are more associated with changes in didactic procedures than with the issue of gender. In this area, treatment is quite different according to gender. Equally distinct are the themes found when it comes to self-care, prescriptions and body prohibitions. In recommendations to girls, patience, cleanliness, temperance, moral courage, order, and sobriety in food and drink are frequent topics; in advice to boys, discussions on courage, drunkenness, alcoholism, physical prowess, suicide, mutilation, work, and laziness arise. The remarkable events regarding the situation of women in the 20th century do not seem to have impacted on school textbooks, both in terms of chosen texts and iconography, with very few exceptions.
\end{abstract}

Keywords: Gender. Equality. Sex. Moral. Hygiene.

Um grande número de artigos de autores francófonos e anglófonos trataram da história dos livros didáticos ${ }^{1} \mathrm{e}$ dos estereótipos de gênero ${ }^{2}$. Quando se tenta, no entanto, explorar especificamente a problemática da igualdade e das relações entre meninos e meninas nos manuais escolares franceses de moral e de higiene nos séculos XIX e XX, a literatura torna-se mais do que limitada, se não quase inexistente, especialmente se olharmos para a questão das injunções corporais. O presente artigo constitui-se como uma visão introdutória do assunto. Para tanto, foram analisados os manuais de moral e de higiene, dando continuidade a pesquisas realizadas alhures (GLEYSE, 2008, 2014, 2020).

Epistemologicamente, baseamo-nos nos escritos de Mary Douglas (1971) acerca dos tabus corporais em nível antropológico, nos de Norbert Elias (1973, 1975) sobre o processo civilizatório e, naturalmente, nos de Michel Bernard (1974), para quem o corpo é "o símbolo usado por uma sociedade para falar de suas fantasias" (BERNARD, 1974, p. 141). Os trabalhos de Michel Foucault $(1969,1975)$ acerca do biopoder e do micropoder também serão evocados.

1 Ao longo do texto, empregaremos as expressões "livros didáticos" e "manuais escolares" como sinônimos. Agradecemos a Cláudia Emília Aguiar Moraes e a Bruno Medeiros Roldão de Araújo pela tradução colaborativa em alguns trechos do presente manuscrito.

2 A produção científica sobre o tema é tão grande que é impossível apontar, nessa ocasião, uma revisão parcial da literatura. Apontamos, a título de ilustração, a coleção Manuels du Monde et Societés (França), os textos do Georg Eckert Institute for Texbooks (Alemanha), a revista History of Education and Children's Literature (Escócia), bem como a revista Gender and Education (multinacional). 
O arquivo explorado é o do Centro de Estudo, de Documentação e de Pesquisa em História da Educação (CEDHRE) ${ }^{3}$, situado na Faculdade de Educação da Universidade de Montpellier. Esse centro de pesquisa abriga a maior parte dos livros didáticos publicados na França desde o início do século XIX, particularmente desde a Terceira República. No tema em estudo, sua coleção está entre as maiores da França e do mundo, contendo mais de 40.000 obras escolares e manuais, 20.000 números de revistas pedagógicas e 6.000 filmes educativos.

Pode-se criticar essa pesquisa por justapor diferentes fontes relativas à moral. Na realidade, trata-se de um corpus homogêneo, não obstante as duas modalidades de livros didáticos. Ambos os tipos de documentos são destinados ao mundo escolar francês e até às escolas coloniais africanas ou asiáticas (ensino primário, primário superior ou secundário). Todos lidam com a moralidade, nomeadamente com as injunções relativas ao corpo.

Metodologicamente, a investigação organizou-se do seguinte modo: inicialmente, listamos os 234 manuais de Moral e os de Instrução Cívica e Leitura Moral, relativos a todos os níveis escolares, bem como os 149 manuais de Higiene (igualmente fornecedores de preceitos morais, em muitos casos além da simples higiene corporal). Em seguida, identificamos, nos textos, tudo que diz respeito aos chamados deveres para consigo mesmo (há também deveres para com a sociedade, para com Deus etc.). Nessa identificação, concentramonos particularmente nas questões corporais, verificando, posteriormente, nesse mesmo domínio, a presença de injunções específicas aos estudantes de cada gênero. Esforçamo-nos em identificar o currículo oculto.

Ao estudar as injunções corporais, os temas recorrentes nos manuais de moral são a preservação do corpo (suicídio, mutilações diversas), a luta contra a preguiça, a luxúria (para os mais velhos), a gula, a raiva, o alcoolismo e a embriaguez ou, inversamente, a valorização do asseio, da prudência, do trabalho, da coragem, da temperança e da sobriedade ${ }^{4}$. Nos livros de higiene, os assuntos concernem ao asseio, à atividade física, à nutrição, ao alcoolismo ou à sobriedade. Detendo-nos sobre esses tópicos, nosso objetivo foi buscar rupturas e continuidades na ordem do discurso (FOUCAULT, 1969, 1971), mormente no que diz respeito ao contexto escolar e social. A maioria dos temas identificados diferencia fortemente as meninas e os meninos em seus comportamentos. O presente manuscrito não poderá estudar todos os temas, selecionando alguns dos considerados mais significativos para o objetivo assumido.

3 Centre d'Étude, de Documentation et de Recherche en Histoire de l'Éducation.

4 Também diagnosticamos a presença da temática do exercício físico (o esporte como tema surge por volta de 1950). Por questões metodológicas, não o abordaremos nesta ocasião. 


\section{A ira e a coragem: estereótipos masculinos}

Já nas primeiras obras de moral estudadas, a ira é apresentada como uma forma de loucura, cujo efeito é transformar o humano em animal:

Como disse um sábio, a ira é uma loucura rápida. Olhe para o homem encolerizado: o seu rosto se contrai, os seus olhos saem da cabeça, a sua boca tem um movimento convulsivo. Pronuncia palavras as quais nunca seriam por ele mencionadas se estivesse tranquilo, palavras que lamentará ter dito. [...] No acesso do seu comportamento, expõe-se a cometer ações irreparáveis, a insultar aqueles por ele mais amados, aos quais deve o maior respeito: os seus amigos, os seus familiares, os seus pais (MÉZIĖRES, 1893 , p. $84-85$, grifo do autor).

Ao contrário, a paciência é uma virtude fundamental para um comportamento civilizado e socialmente aceitável, a fortiori, para uma mulher. Em qualquer caso, se a ira é um pecado capital para o catolicismo, em si mesma ela não é condenada pelos livros de moral. Condena-se, na verdade, a sua consequência - isto é, o algoritmo fatal por ela possivelmente engendrado -, o qual leva aos piores extremos: matar alguém, por exemplo.

[O homem irado] não sabe mais o que faz. [...] A discussão começa, depois se anima, fica acalorada, palavras violentas são ditas, e das palavras chegase aos socos. Assim, sem querer, nos arroubos imoderados da fúria, amigos mataram amigos, irmãos mataram irmãos, filhos feriram até seus pais. Os culpados se desesperam quando o mal é feito. Eles teriam poupado muito remorso se tivessem começado a resistir cedo às tentações da ira (MÉZIÈRES, 1893, p. 85, grifo do autor).

De forma reiterada, as obras evocam, nessa temática e na discussão sobre a embriaguez, como veremos adiante, o famoso exemplo de Alexandre, o Grande, matando seu amigo. Observa-se, nesses casos, a presença exclusiva de homens. Autores célebres da Antiguidade são frequentemente citados. Podemos procurar mulheres nesses capítulos dos manuais, mas não as encontraremos, embora tais obras sejam destinadas a ambos os sexos. A exceção consiste no apelo à doçura 
feminina para apaziguar a cólera masculina. A iconografia ilustrativa, abaixo apresentada, é reveladora dessa ausência das mulheres.

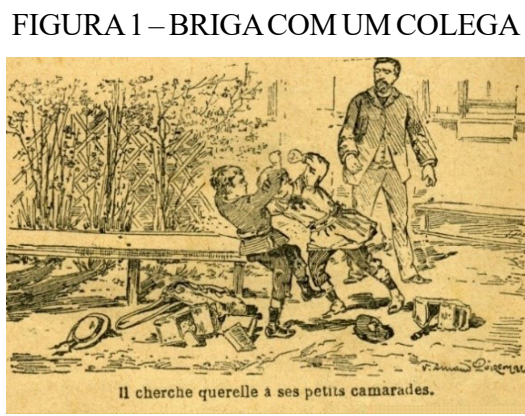

FONTE: MÉZIÈRES, 1893, p. 91.
FIGURA2-CRIANÇAENCOLERIZADA

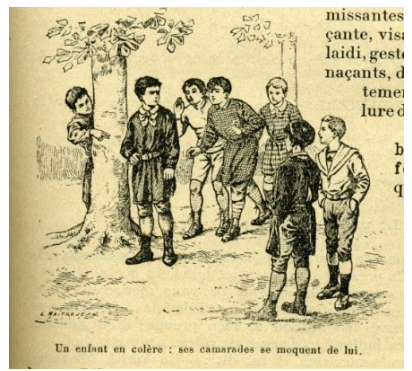

FONTE: BRÉMONT; MOUSTIER, 1920,p. 133.

Nesse capítulo específico dos manuais, um certo número de comportamentos considerados calmos é associado às mulheres e, às vezes, mais raramente, a famosas personalidades inglesas. É o caso do Sr. Humpden, membro do parlamento cujo autocontrole é altamente valorizado. Ademais, as obras destinadas especificamente às meninas insistem muito sobre a prática da paciência, a qual deve ser levada a cabo principalmente por elas.

Uma mulher é quase sempre descrita como a reguladora da tranquilidade no lar. Em 1895, um manual dá o seguinte título a um capítulo: "Necessidade de paciência para as mulheres". Esse tópico se conclui com a seguinte máxima, provavelmente a ser aprendida de cor: "Se a doçura não for a primeira virtude de uma mulher, talvez seja seu mais poderoso meio de felicidade" (SEIGNETTE, 1895, p. 59). Inversamente, o trabalhador, sobretudo o bêbado ou intemperado, é o vetor da violência e da ira.

No nível didático, às classes de crianças menores são dirigidas fábulas e modelos identificatórios, ao passo que às turmas de estudantes maiores os ilustres predecessores e as máximas a serem aprendidas de cor são estratégias das quais se lança mão mais habitualmente. Nessa direção, figuram as "Pequenas Leituras Morais" - da autoria de Marie Pape-Carpantier e do Sr. e da Sra. Charles Delon (1900), obra publicada pela Editora Hachette. Destinado ao primeiro ano preparatório, esse manual emprega fábulas personalizadas e identificatórias, com vistas a prender a atenção da criança através de cenas da vida cotidiana. Quando se trata da questão da ira, no entanto, o alvo das histórias lidas pelo professor nunca são as meninas: 
A ira. Que algazarra ouvimos no quarto! - É o pequenino Armand que está com raiva. Ele quebrou todos os seus brinquedos, derrubou uma cadeira. Ele chora, ele grita, ele provoca... Ele bate os pés no chão e fecha os punhos. Ele tem os olhos e o rosto vermelhos: está descabelado e sua fisionomia traz uma careta horrível. [...] Sua mãe o segura gentilmente; ela o leva até o espelho. Armand se vê, se acha feio e retoma sua calma (PAPE-CARPANTIER; DELON, 1900, p. 23).

Armand, nesse caso, está no centro da parábola. As meninas não parecem estar presentes nesse capítulo específico dos manuais de moral, repleto de recomendações. Os livros de higiene, evidentemente, não tratam desse tema. Como em todos os outros assuntos a serem discutidos, a partir dos anos 1950 a maioria dos textos foi personalizada (levando em conta a faixa etária dos alunos) e, sobretudo, cada vez mais formulada em termos de apropriação pessoal ("eu faço", "eu”), e não mais em termos de dever ("nós devemos", "é necessário").

A coragem física também está vinculada a meninos e homens. A modalidade moral dessa virtude, por outro lado, é mais conectada às meninas. Os exemplos concernentes à guerra são numerosos nos livros de moral. Ao longo do século XX, é recorrente a imagem do cavaleiro de Assas sacrificando-se pelo batalhão de Auvérnia, gritando durante a batalha de Clostercamp: "Para mim, Auvérnia; eles são nossos inimigos!". Forja-se, assim, a "narrativa nacional".

A partir da década de 1930, a coragem liga-se ao trabalho, ao menino que salva outro do afogamento pondo em risco sua própria vida, e cada vez menos à guerra. Nesse sentido, os manuais da época diferenciam-se dos anteriores. A virtude em questão vincula-se similarmente a uma criança trabalhadora em condições difíceis, bem como à prudência. De fato, a coragem irracional é, pelo menos desde 1920, se não mesmo a partir da virada do século, considerada prejudicial, pois pode se relacionar ao suicídio. A prudência consiste em ser corajoso, mas sem correr risco de morte desnecessariamente. Logo, a temperança permite distinguir entre coragem verdadeira e falsa. Um livro didático de 1920 nos traz a seguinte reflexão:

A coragem não pertence apenas ao soldado, ela não pertence somente ao homem que luta Para defender um país que pensa e trabalha!

A própria vida é um campo de batalha

Onde cada trabalhador tem sua própria coragem

Fugir do trabalho a fazer ainda é fugir. 
[...] A vida é um combate. Eu quero cumprir minha tarefa Aquele que foge do campo de trabalho é um covarde [Jean Aicard, Livre des Petits, Delagrave, Edit.] (BRÉMONT; MOUSTIER, 1920, p. 152).

Nessa citação do manual de Brémont e Moustier, vemos a associação do trabalho, tema do capítulo anterior deste mesmo livro, com a coragem. Esta, porém, manifesta-se em sua versão regular e prudente, poderíamos dizer apolínea e não dionisíaca, participando mais da razão do que da pulsão, paixão ou emoção.

A partir dos anos 1940, a coragem foi cada vez mais associada ao esporte e ao exercício físico, especialmente à possibilidade de ultrapassar os próprios limites para alcançar um feito esportivo (a famosa "superação de si”) (GLEYSE, 2018). A dimensão física da coragem, contudo, permanecerá essencialmente masculina. Com efeito, se continuarmos a tomar a referência da heroicidade, após a Segunda Guerra Mundial é cada vez mais frequente designar as dificuldades cotidianas enquanto atos de coragem: vencer o medo, a tentação, produzir um esforço físico ou intelectual, trabalhar duro. Fala-se, finalmente, de heróis do dia a dia.

Variadas técnicas didáticas são utilizadas nesse campo. Como sempre, podemos encontrar o recurso aos autores de prestígio, homens famosos, heróis de guerra, mas também a outras crianças, convocadas enquanto modelos de identificação:

Crianças brincam. Uma delas cai, machuca gravemente a cabeça e perde a consciência. Assustados com a visão de sangue e a imobilidade da criança, seus colegas caem na fraqueza de fugir. Somente um tem a presença de espírito para lavar a ferida do camarada e, depois de enfaixá-la com seu lenço, ajudá-lo a chegar até a casa de seus pais, quando o socorro chega. Essa criança mostrou coragem (CURÉ; HOUZELLE, 1895, p. 141).

Fica claro que a coragem física não é um ato irrefletido, mas uma atitude racional ao alcance de todos... os meninos. Para as meninas, apenas a coragem moral muitas vezes estará presente, junto à gentileza, à paciência ou até à teimosia. Ainda sobre as técnicas didáticas, salientamos o uso das relações de oposições binárias: 
O homem corajoso: conserva sua vontade e sua plena razão. Nunca se desespera. Supera os obstáculos. É valoroso especialmente no infortúnio. Cumpre sempre seu dever. O homem temeroso: sua vontade e razão estão aniquiladas. Mantém uma resignação passiva e humilhante. Deixa-se levar pelas dificuldades. Perde sua compostura em perigo ou infortúnio. Cumpre seu dever somente quando há pouco mérito em fazê-lo (CURÉ; HOUZELLE, 1895, p. 141).

Para os manuais, parece decisivo distinguir claramente as duas características humanas, bem como proceder a uma diferenciação entre temor, covardia e prudência. Esta última virtude é facilmente combinada à coragem. De fato, uma coragem inconsciente não é apreciada. Na verdade, valoriza-se, numa espécie de oximoro, a "coragem prudente" ou, pelo menos, a coragem razoável e sensata. As imagens sobre esse assunto, de maneira similar à iconografia relativa à ira, redobram o discurso, sempre excluindo as meninas dessa ordem discursiva. Invariavelmente, os meninos salvam as meninas de bois enfurecidos, lobos selvagens ou quaisquer outros perigos.

\section{FIGURA 3 - O MENINO SALVA A MENINA}

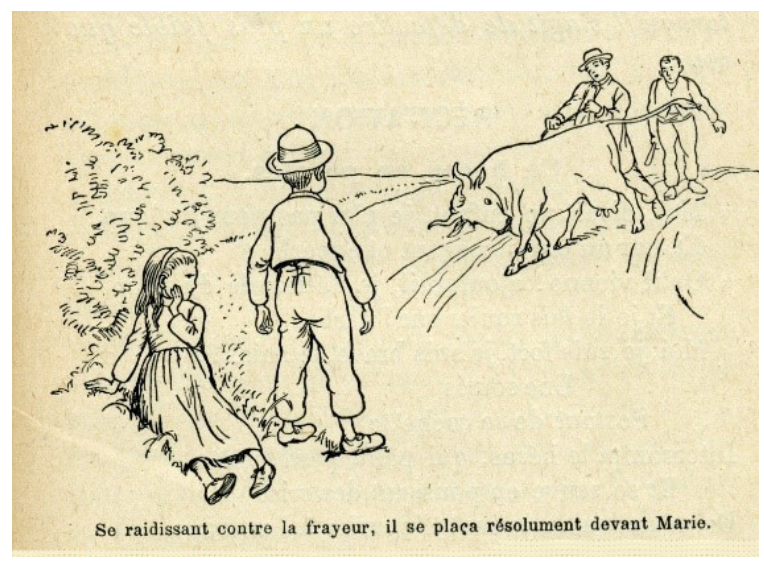

FONTE: PIERRE; LETRAIT; BODIN, 1909, p. 93.

As meninas ou mulheres serão corajosas em situações da vida diária nas quais o aspecto físico é menos importante, tais como acompanhar crianças ao médico ou não cometer suicídio em uma situação de angústia. Mesmo quando se trata de coragem diante de doença, da deficiência ou de carregar "um fardo da 
vida", os homens são apontados como exemplos. Em geral, tanto nas histórias quanto na iconografia, inclusive nos manuais endereçados a ambos os sexos, as mulheres estão pouco representadas.

FIGURA 4 - MULHER EM SITUAÇÃO DE CUIDADO

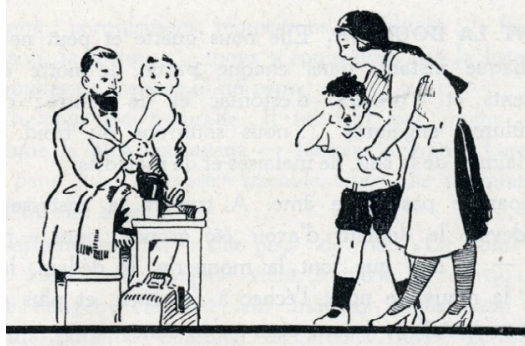

FONTE: EISMENGER; COUPIN, 1928, p. 73.

\section{FIGURA 5 - MULHER NA MISÉRIA}

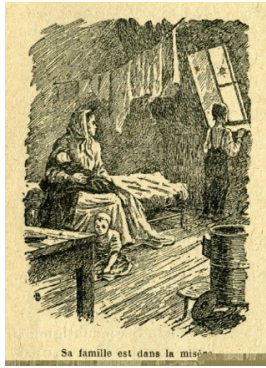

FONTE: BRÉMONT; MOUSTIER, 1920, p. 121.

\section{O trabalho e a preguiça: ainda estereótipos da masculinidade}

A iconografia abaixo diz quase tudo sobre o lugar das meninas e das mulheres quando se trata de situações relativas ao trabalho ou à preguiça. Em ambos os casos, nos livros destinados a ambos os sexos, elas estão quase ausentes.

FIGURA 6 - O TRABALHO
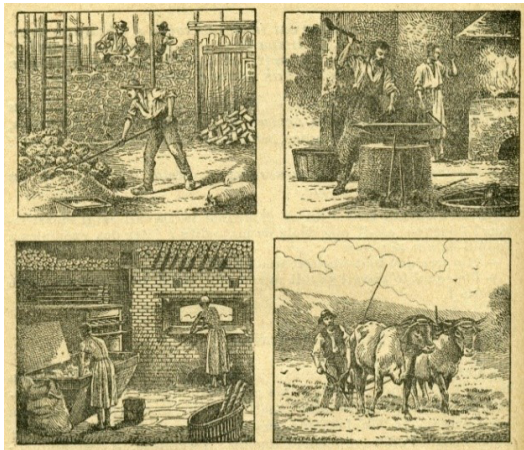

FIGURA 7 - A PREGUIÇA

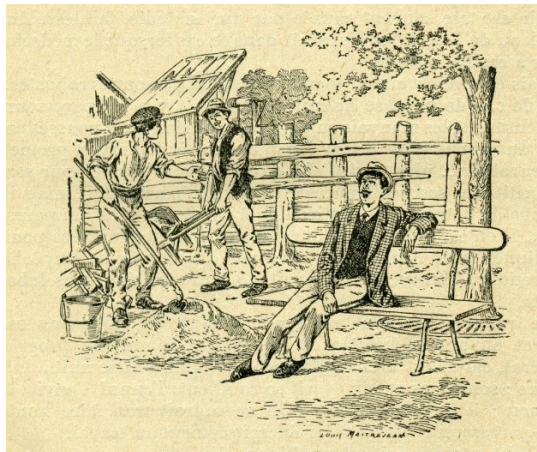

FONTE: BRÉMONT; MOUSTIER, 1920, p. 158. FONTE: BRÉMONT; MOUSTIER, 1920, p. 164. 
Na melhor das hipóteses, nós as reencontraremos nas imagens acerca do trabalho doméstico e da esfera familiar, até os anos 1950. Nesses âmbitos, inserem-se as raras ilustrações nas quais as mulheres estão presentes (por exemplo, quando se trata de deformidades na coluna vertebral, consequências do labor feminino).

FIGURA 8 - MÁ POSTURA

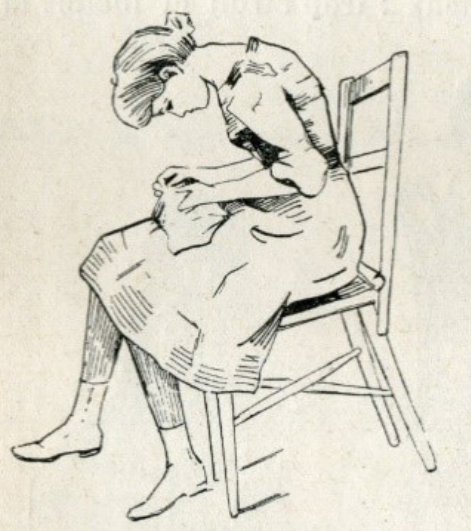

FIGURA9-PRODUÇÃO DAESCOLIOSE

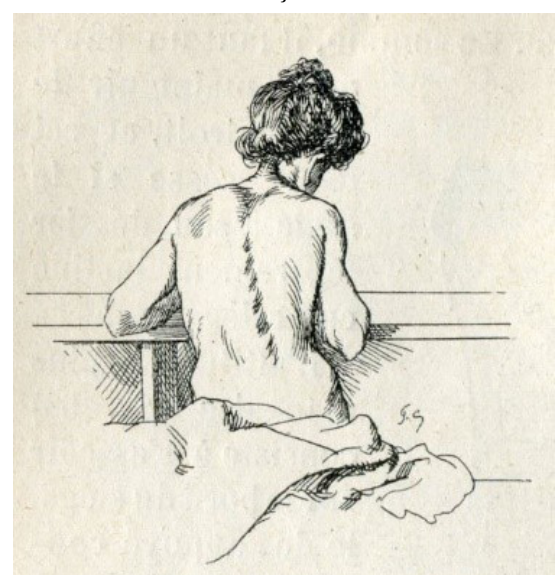

FONTE: NONUS; POIRE-CHOQUET, 1890, p. 27.

Entretanto, a ausência das mulheres retorna nas parábolas ou histórias edificantes, ocasiões nas quais os homens surgem como personagens. Na melhor das hipóteses, os discursos são indiferenciados, mas na maioria das vezes reforçados por uma iconografia masculina.

Com a citação seguinte, encerra-se o capítulo dedicado a esse assunto em vários manuais: "Glória ao trabalho! Glória ao homem do campo, glória ao homem que fecunda o solo! Picard, Breton, Limousin, Cévenol, glória àquele que conduz os bois ao pasto! Glória ao homem campesino!" (LAUNEY, H.; LAUNEY, J.; RASCAL, 1921, p. 135). Outras máximas como esta são igualmente apresentadas: "O trabalho enriquece, a preguiça empobrece". A maioria dos manuais tem um capítulo sobre essa temática, não raro intitulado Trabalho e preguiça, embora às vezes a discussão gire apenas em torno do labor.

$\mathrm{Na}$ França, é bastante conhecido o mote repetido ao infinito nos livros didáticos: "A preguiça é a mãe de todos os vícios". A preguiça é também um pecado capital no catolicismo. Nos manuais, percebemos um enaltecimento do trabalho em detrimento da depreciação da preguiça. Nesse campo, todos os procedimentos pedagógicos são convocados para promover o aprendizado 
do que é descrito como uma lei da natureza, pelo menos no início do século. Mais tarde, a seguinte frase será constantemente empregada: "O trabalho é a lei humana" (POIGNET; BERNAT, 1919).

Além disso, o trabalho manual - talvez mais que o intelectual - é amiúde salientado, sempre para os homens, especialmente no início do século, localização temporal que pode ser compreendida tendo em vista o contexto socioeconômico da época. A figura do "Carpinteiro Brissot" (um homem, é claro) está particularmente presente nas obras. Ele se diz feliz com seu ofício e afirma: "o trabalho [...] é a minha saúde. $\mathrm{O}$ dia em que meus braços não pressionarem mais a plaina, não mais comerei com o mesmo apetite e não mais terei o mesmo vigor" (DEVINAT, 1920, p. 131).

Nesse assunto, uma fábula de La Fontaine intitulada "O lavrador e seus filhos" (novamente, apenas homens) retorna regularmente como leitmotiv. O texto começa com a afirmação "O trabalho é doloroso, assuma o esforço: falta pouco para o fundo" e termina com a frase a seguir: "mostrar-lhes, antes de morrer, que o trabalho é um tesouro". Naturalmente, para os alunos dos cursos elementar e médio, a fábula deve ser memorizada. Um livro de 1920 fala diretamente da "santidade do trabalho" (BRÉMONT; MOUSTIER, 1920, p. 158). Essa obra também especifica: "Todo trabalho é útil, seja intelectual ou manual, desde que feito com coragem e inteligência. Não existem ofícios nobres ou degradantes. Todos os trabalhadores conscientes têm direito ao respeito e à estima" (BRÉMONT; MOUSTIER, 1920, p. 161).

Para muitos sociólogos contemporâneos, de 1880 a 1968, as práticas laborais se constituíram no centro da sociedade. Em contrapartida, conforme outros pesquisadores, o lazer parece tê-lo substituído a partir dos anos 1980 e 1990 (DUMAZEDIER, 1962, 1989; DURAND; MERRIEN, 1991). As edições dos manuais de moral da coleção estudada terminam em 1964, enquanto as de higiene seguem publicados até 1974 . Seria difícil defender que a criatividade sobre a temática agora discutida, nesses manuais, não seria fruto justamente da crescente presença do trabalho intelectual no tecido social. Em qualquer caso, o labor permanece essencialmente manual, físico e masculino em todo o corpus estudado.

Ademais, nenhum lugar é dado às mulheres nesse domínio, muito embora elas já fossem numerosas na indústria têxtil, no trabalho terciário e em certas tarefas fabris de precisão, e não obstante reivindiquem direitos de existir no espaço social e laboral desde 1920. A exceção, como vimos, consiste em alguns serviços de costura ou cuidados domésticos. 


\section{O asseio e a higiene: práticas muito femininas}

O tema do asseio está presente nos livros didáticos de moral e higiene. Essa segunda modalidade, evidentemente, fundamenta-se em preceitos científicos e se concentra sobretudo na luta contra os micróbios, desde a descoberta desses microrganismos. Nos manuais de moral, a limpeza física é de certa forma o reflexo de uma alma pura, até o momento em que esse tipo de discurso religioso (ligado ao sacramento do batismo, por exemplo) seja eliminado pelo discurso científico a partir dos anos 1930. Nesse domínio, ao contrário do anterior, personagens femininas estão extremamente representadas tanto na iconografia quanto nos textos oferecidos às crianças para leitura. A ideia de uma mulher suja parece completamente insuportável para os autores desses livros.

Malgrado o curso de Elie Pécaut não faça distinção entre meninas e meninos (mas lembremos que ele é voltado para os homens), propõe um asseio diário cujos procedimentos poderiam ser considerados simplórios aos nossos olhos, no início do século XXI:

O hábito de lavar o rosto e as mãos toda manhã é suficiente sobre esse ponto, o higienista não teria grande coisas a dizer. Mas é preciso notar que muitas pessoas, sobretudo numerosas crianças, o praticam de maneira muito sucinta (PÉCAUT, 1882, p. 100).

\section{FIGURA 10 - ABLUÇÕES FRIAS PARA AS CRIANÇAS}

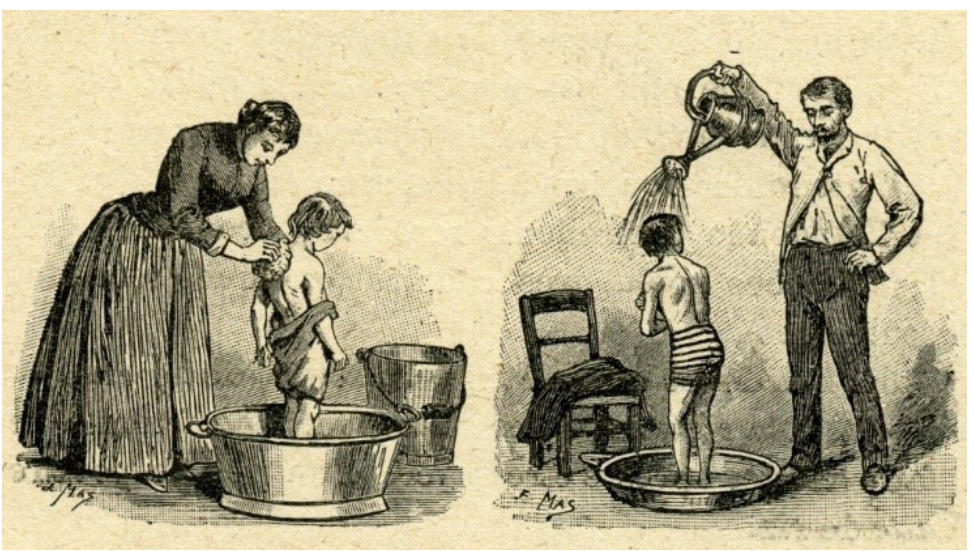

FONTE: GALTIER-BOISSIERE, 1921, p. 131. 
Os cabelos eram lavados apenas uma vez por semana e recomendava-se tomar banhos quinzenais, no final do século XIX. Essa injunção é surpreendente, uma vez que os espaços públicos ofertados pelo município para os banhos de duchas são raros na França daquela época, caracterizada por ser bastante rural. Somente a burguesia podia tomar banho tão facilmente como hoje. A maioria das casas não está equipada com chuveiros, muito menos com banheiras. Para esse fim, usam-se as cubas ou simplesmente grandes bacias, normalmente utilizadas na única área aquecida da casa: a cozinha. No ambiente camponês, as abluções são não raro realizadas em rios e outros pontos de água.

No entanto, quando se trata de asseio e sujeira, os destinatários das parábolas são principalmente as meninas. Um texto e algumas imagens de um manual de 1920 o atestam:

Berthe Longuet sempre tem as mãos sujas. Um círculo de impurezas recobre seus pulsos; uma camada de sujeira se estende por seus dedos; uma borda preta e oleosa contorna suas unhas; seu rosto parece sem brilho e frescor. $[\ldots]$

"Então vá lavar as mãos", diz sua mãe. [...]

Lave-se - eis o eterno refrão que cantam para ela. [...] Você será infeliz por sua própria culpa. E o que é mais grave, você será muito desagradável para os outros. [...] Quando temos a honra de ser uma pessoa humana, senhorita, é preciso saber se respeitar. Estar sujo é faltar com o respeito a si mesmo (DEVINAT, 1920, p. 113-114, grifo do autor).

\section{FIGURAS 11 E 12 - LOÇÃO FRIA E FRICÇÃO APÓS A LOÇÃO}

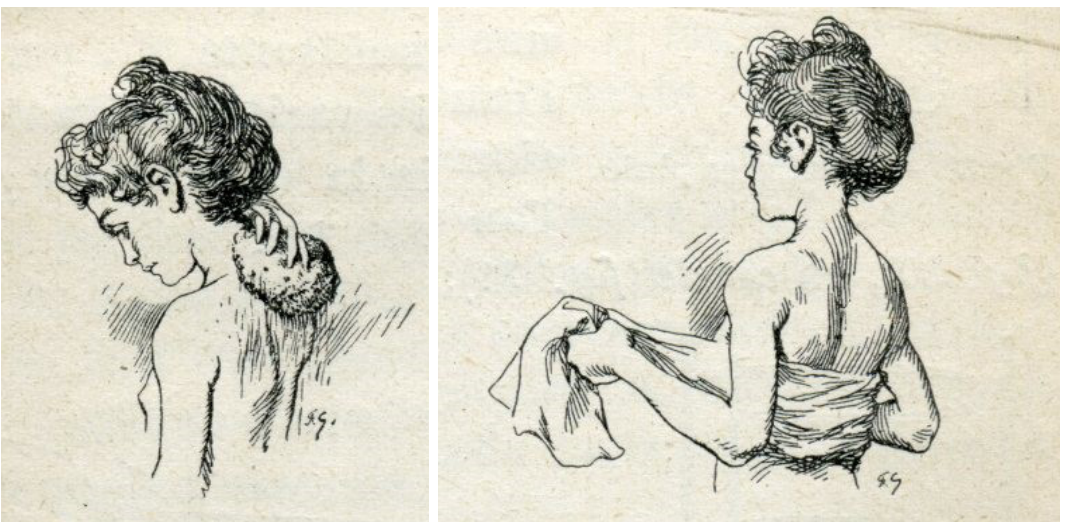

FONTE: CAUSTIER; MOREAU-BERILLON, 1911, p. 65. 
Por outro lado, mudanças profundas ocorrem ao longo do tempo, sempre no nível didático, pois, como nos outros temas, experimentamos a transição de uma injunção, que às vezes mobiliza autores ilustres a fim de se legitimar para uma personalização cada vez maior. O excerto a seguir, por exemplo, testemunha a perspectiva da prescrição moral: " 1 . O asseio testemunha o respeito que temos pela sociedade e por si mesmo (Bacon). [...] 2. Aquilo que a pureza é para a alma, o asseio é para o corpo (Epíteto)" (DESPOIS; LABERENNE, 1910, p. 123). Em contrapartida, pouco a pouco serão notados textos cujo escopo é a apropriação, pelo próprio sujeito, das determinações higiênicas - o que se vê pelo aparecimento do pronome $\mathrm{eu}$-, inclusive no caso das crianças menores:

Eu sinto muito prazer em ser muito limpo. "Todos os dias $e u$ cuido do meu rosto, das minhas mãos, dos meus dentes, do meu cabelo". Eu limpo minhas roupas, meu chapéu, meus sapatos; tomo banho com bastante frequência. $E u$ acho a impureza repugnante. $E u$ não gosto de apertar uma mão suja ou beijar uma cara suja (BOURCEAU; FABRY, 1949, p. 200, grifo nosso).

Podemos constatar a existência inclusive de proposições hedonistas, beirando o erotismo, nas quais as meninas estão sempre na vanguarda das preocupações. Assim, em um livro do final do período estudado, um texto de Colette poderia praticamente aparecer em uma coleção erótica, quando na verdade se destina a crianças da escola primária:

Que prazer sentir essa chuva fina a cair sobre mim, em que mil pequenas agulhas me picam a pele! A água deliciosamente morna escorre ao longo da minha coluna vertebral. Prazer também em ensaboar vigorosamente com um sabão delicadamente perfumado (VILLARD, 1964, p. 6).

Além disso, na iconografia, quase sempre as mulheres se encarregam do asseio das crianças, com raras exceções: 
FIGURA 13 - CRIANÇA EM UMA CUBA

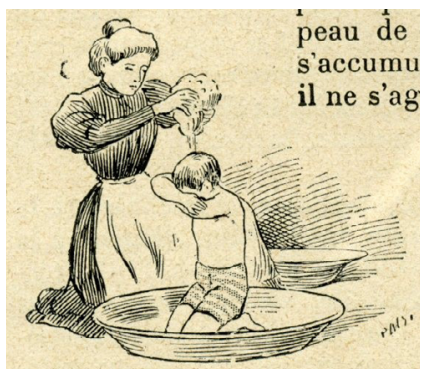

FONTE: PIZON, 1930, p. 178.
FIGURA 14 - ABLUÇÕES FRIAS PARA AS CRIANÇAS

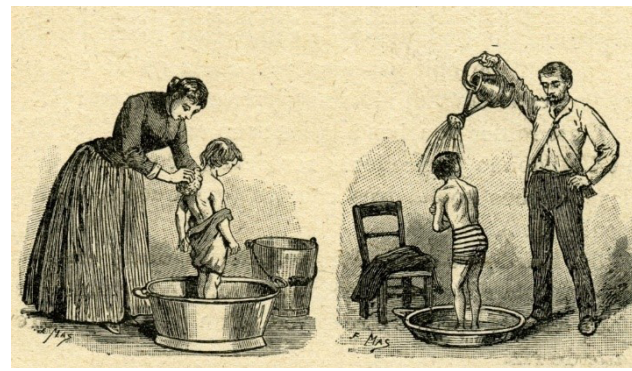

FONTE: GALTIER-BOISSIERE, 1921, p. 131.

Podemos perceber, portanto, como durante o século XX os manuais franceses de moral e higiene funcionaram com base em preconceitos e estereótipos de gênero relativos aos papeis sexuais. Apesar de haver certas perturbações nessa ordem no curso do tempo, elas dizem respeito mais às dimensões pedagógicas do que aos estereótipos. A igualdade entre meninas e meninos está longe de ser alcançada nessas obras, ao menos no que concerne ao compartilhamento das tarefas laborais e domésticas, bem como à divisão de outras atividades associadas a condutas socialmente sexuadas. Os estereótipos de gênero também estão manifestos nas temáticas da relação com as bebidas alcoólicas e a embriaguez.

\section{Mulheres para acalmar homens beberrões e alcoólicos com a ordem e a boa comida}

Quaisquer que sejam a modalidade do manual e o período de sua publicação, o alcoolismo é fortemente criticado, apesar de o consumo moderado de vinho, em particular, ser aceito - especialmente no início do século XX. Por outro lado, as manifestações de alcoolismo e, principalmente, a embriaguez são rejeitadas: nas obras de higiene, a recusa se funda, naturalmente, em razões de saúde; nos livros de moral, a decadência humana e social resultante da embriaguez é empregada como base para a rejeição: 
Não se deve beber álcool

- "A embriaguez é um vício vergonhoso". Ela inspira horror, pois faz o homem perder a razão, degradando-o; também inspira medo, porque transforma o homem bêbado em um animal furioso e, portanto, perigoso. - O abuso do álcool faz mais vítimas do que a peste ou a cólera. Causa todos os tipos de doenças, torna uma pessoa idiota ou louca. "Absterme-ei de licores fortes" e resistirei a toda má atração (BOURCEAU; FABRI, 1949, p. 214).

Muitas vezes, descreve-se um círculo vicioso, semelhante à estratégia da qual se lançou mão no tema da ira. O exemplo de Alexandre, o Grande, assassinando seu melhor amigo é, novamente, trazido à baila a fim de edificar os alunos mais velhos. Supostamente, a embriaguez e o alcoolismo levariam aos mesmos comportamentos criminosos e antissociais, tanto em relação a estranhos quanto aos conhecidos. Os beberrões são sempre homens, nunca as mulheres. Estas, ao contrário, tentam pacificar as situações e regularmente são vítimas de homens embriagados.

A imagem abaixo mostra a esposa honrada, tentando desviar seu marido da embriaguez na qual ele imergiu. A fada verde - ou seja, o absinto - é, então, considerada o pior inimigo da mulher virtuosa. As Ligas de Virtudes, com efeito, serão criadas não poucas vezes por iniciativas femininas, e se mobilizarão sobretudo pela proibição da bebida em xeque. Tal posicionamento será registrado no dia 16 de março de 1915, na França:

O mais conhecido e mais mortífero dos aperitivos é o absinto, verdadeiro veneno lento, que mata os que o usam diariamente, reduzindo-os ao mais miserável estado (epilepsia, mania); o efeito desse terrível licor não se esgota sobre o infeliz que morre; os seus filhos, desde o nascimento, são marcados pelo triste selo da idiotice e podem mais tarde herdar a epilepsia paterna (PÉCAUT, 1882, p. 42-43). 
FIGURA 15 - A MÃE DE FAMÍLIA BUSCA O MARIDO NO BAR

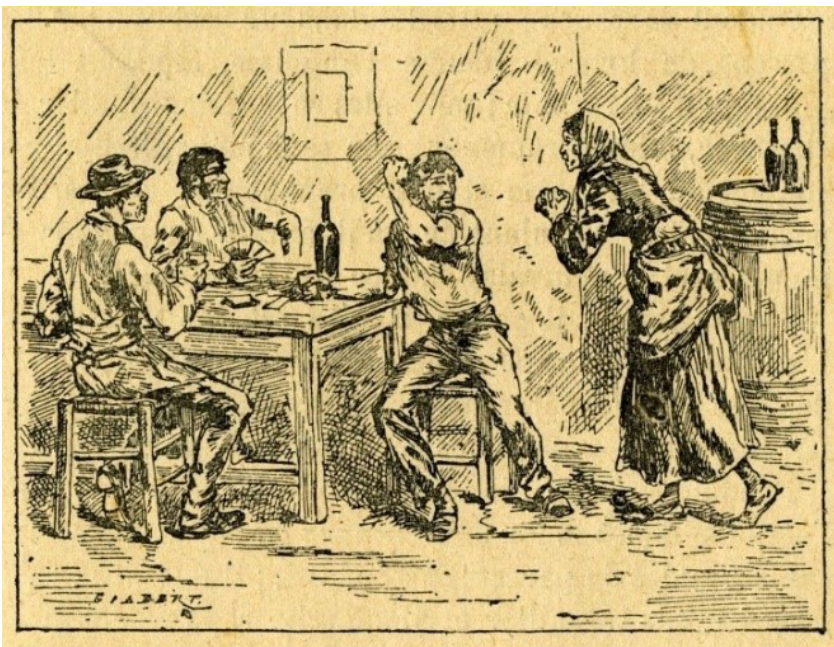

FONTE: MÉZIÈRES, 1893, p. 51.

Em todos os casos, a temperança ao beber (álcool e outras bebidas) e ao comer é prescrita tanto nos manuais de moral quanto nos de higiene. Ora, se a gula é um pecado capital e a temperança, por consequência, uma virtude, cujas raízes se encontram no catolicismo, com o álcool a situação é distinta. Não obstante seu consumo seja interditado no Islã, ele não o é na Igreja católica, instituição relativamente poderosa no início do século XX. O sangue de Cristo na Eucaristia é simbolizado por um cálice de vinho, então chamado de "vinho de missa". Numerosos monastérios fabricam várias bebidas alcoólicas, desde a cerveja dos monges trapistas belgas à dos cartuxos dos Alpes.

Todas as prescrições relativas às doses permitidas dirigem-se sempre para homens ou crianças. As mulheres nunca estão envolvidas nas recomendações acerca de bebidas alcoólicas ou da embriaguez:

Um trabalhador de força pode beber por dia 1 litro de vinho a 10 ou $12^{\circ}$; mas um homem sedentário só deve beber, no máximo, meio litro. Às crianças oferecemos uma quantidade pequena e sempre misturada em água. $\mathrm{O}$ vinho misturado com alimentos tem menos ação; recomenda-se não beber entre as refeições (FOULON-LEFRANC, 1944, p. 44, grifo do autor). 
As esposas, no entanto, serão correntemente culpadas pelo alcoolismo de seus cônjuges. Nesse caso, evoca-se a organização, que consoante os manuais deve ser uma das principais qualidades femininas. Portanto, a desorganização da mulher causaria a embriaguez do marido:

Vemos muitos jovens sóbrios tornarem-se maridos e pais alcoólatras! Ainda nesse caso é necessário acusar a ignorância, a ignorância da mulher, sua desordem, os defeitos de seu caráter. Quantas esposas de operários e de assalariados ignoram a arte de gerir uma casa! Não aprenderam a cozinhar e, em vez de alimentos saudáveis, variados e apetitosos, servem alimentos mal cozidos ou queimados, e uma charcutaria picante que provoca sede. Elas não aprenderam a fazer a limpeza, e as camas desarrumadas, as roupas por lavar, empilhadas em cadeiras ou penduradas em fechaduras de janelas, os utensílios de cozinha espalhados por toda parte, a poeira presente, criam um interior onde pessoa alguma se sente bem [...] Quantos homens são assim impelidos ao cabaré pelo descuido de uma mulher e pela desordem de um lar pouco acolhedor! (FOULONLEFRANC, 1944, p. 26, grifo do autor).

Essa constatação é totalmente paradoxal, pois, na verdade, as mulheres salvam os homens da bebedeira, segundo os mesmos manuais de moral ou higiene:

Quando a mulher for a cozinheira organizada e limpinha, a dona de casa hábil e cuidadosa, que saiba variar os alimentos, apresentá-los com bom gosto e fazer das refeições uma pequena festa calma e alegre; quando for a companheira doce, de igual humor, a mãe atenta que sabe tornar o lar agradável e reconfortante para todos, que sabe ensinar aos filhos a ternura e o respeito pelo pai trabalhador, acredite que o lar luminoso e pacífico será raramente trocado pelo bar enfumaçado e barulhento (FOULON-LEFRANC, 1944, p. 27-28).

As mulheres são muitas vezes descritas como vítimas de espancamentos cometidos por homens bêbados; outros textos falam mesmo do assassinato da esposa e dos filhos, perpetrado por um marido em um ataque de fúria alcoólica. Em contrapartida, durante parte do século XX, as obras se referem a uma suposta transmissão hereditária da doença ou da loucura do alcoólico aos seus filhos. Mesmo em meados desse século, todavia, não se aconselhava aos trabalhadores as mesmas doses de álcool hoje recomendadas, como apontamos anteriormente. 


\section{Conclusão}

O imaginário de uma "mulher fraca" assombra todos os manuais de moral e higiene na França desde o final do século XIX até o segundo terço do século $\mathrm{XX}$, contribuindo, desse modo, para ensinar essa compreensão aos alunos. $\mathrm{Na}$ mesma perspectiva, a imagem de uma mulher voltada à estética, à paciência, ao espaço doméstico, à organização e à limpeza é apresentada em demasia. $\mathrm{O}$ homem, por outro lado, é descrito como fisicamente corajoso, forte, mas também alcoólico, beberrão, violento, suicida, trabalhador ou preguiçoso.

Embora no início do século XX e no final do século XIX o processo de segregação seja muito explícito, pois o gênero é, na maioria das vezes, naturalizado no sexo, o movimento que leva à igualdade de gênero nessas obras é mais do que tênue. A mudança de mentalidades e prescrições, caso exista, deve ser procurada no campo da atividade física, área na qual a visibilidade feminina começou a se tornar real a partir dos anos 1950. Os temas permanecem, entretanto, largamente diferenciados por gênero. Testemunhamno tanto a iconografia quanto os próprios textos, regularmente funcionando de forma tautológica.

No corpus analisado, as rupturas mais significativas podem ser percebidas na dimensão didática. No início do período estudado, propõe-se essencialmente injunções do tipo "você deve" e "é preciso". Ao alcançarmos a segunda metade do século XX, personaliza-se o aprendizado cada vez mais. A aprendizagem passa a ser "internalizada": usa-se cada vez mais o "eu", "eu faço", "eu tenho", lançando mão inclusive de posições hedonistas, ou seja, associando o prazer a certas práticas como o banho ou o exercício físico.

Assim, à pergunta levantada no início do artigo - os manuais escolares franceses de moral e higiene são sexistas, desde o final do século XIX até o último terço do século XX? -, a resposta é afirmativa. Nessa direção, esses materiais serviram para ensinar as diferentes modalidades de sexismo através dos campos específicos da moral e higiene. Para tanto, fundamentaram-se, ao menos até o primeiro terço do século XX, em prescrições religiosas essencialmente católicas - ou, mais amplamente, cristãs -, notadamente os sete pecados capitais e as suas correspondentes sete virtudes cardeais. Resta saber se essa prática pedagógica realmente deu frutos e, por conseguinte, se os alunos realmente aprendem o que lhes era ensinado. Isso exigiria uma investigação mais aprofundada.

De fato, este estudo ajudaria a validar a ideia, já trabalhada por Nicole Mosconi (1989), segundo a qual a escola funciona ou funcionou na lógica do aprendizado implícito de um "masculino neutro". No mínimo, a instituição 
escolar estaria alicerçada sobre o aprendizado de papéis masculinos e femininos distintos, destacadamente no que concerne às condutas moral e de higiene corporal, materializadas em variados comportamentos. Os livros de moral e higiene, através de currículos ocultos, provavelmente ensinam mais sobre ser um estudante do sexo feminino e do sexo masculino do que sobre ser um aluno em geral.

\section{REFERÊNCIAS}

BERNARD, Michel. Le Corps. Paris: Delarage, 1974.

BOURCEAU, Emile; FABRY, Raymond. Lectures expliquées avec enseignement moral et civique. Paris: Editions de l'Ecole, 1949.

BRÉMONT, Emile; MOUSTIER, D. L'éducation morale et civique à l'école. Cours moyen et cours supérieur. Paris: Delalain, 1920.

CAUSTIER; MOREAU-BERILLON. Hygiène. Paris: Vuibert \& Nony, 1911.

CURÉ, Jules; HOUZELLE, François. Sommaires de leçons de morale à l'école primaire. Paris: E. Belin, 1895.

DESPOIS, André; LABERENNE, Marie-Louise. Lectures morales. Ecoles primaires supérieures, Ecoles professionnelles. Paris: Delagrave, 1910.

DEVINAT, Emile. Livre de lecture morale. Paris: Larousse, 1920.

DOUGLAS, Mary. De la souillure: Essai sur les notions de pollution et de tabou. Paris: Maspero, 1971.

DUMAZEDIER, Joffre. Vers une civilisation du loisir. Paris: Seuil, 1962.

DUMAZEDIER, Joffre. La Révolution culturelle du temps libre (1968-1988). Paris: Méridien Klienksieck, 1989.

DURAND, Jean-Pierre; MERRIEN, François-Xavier. Sortie de siècle. Paris: Vigot, 1991 EISMENGER, G.; COUPIN, H. Le Corps Humain, Hygiène. Premier cycle. Classe de Troisième. Paris: Nathan, 1928.

ELIAS, Norbert. La Civilisation des mœurs. Paris: Calmann-Lévi, 1973.

ELIAS, Norbert. La Dynamique de l'Occident. Paris: Calmann-Lévi, 1975.

FOUCAULT, Michel. L'Archéologie du savoir. Paris: Gallimard, 1969. 
FOUCAULT, Michel. L'ordre du discours: Leçon inaugurale au Collège de France prononcée le 2 décembre 1970. Paris: Gallimard, 1971.

FOUCAULT, Michel. Surveiller et punir. Paris: Gallimard, 1975.

FOULON-LEFRANC, Louise. La Femme au foyer. Paris: Éditions de l'École, 1944.

GALTIER-BOISSIERE. Notions élémentaires d'Hygiène pratique. Paris: ArmandColin, 1921.

GLEYSE, Jacques. Les représentations iconographiques des pratiques corporelles dans les Manuels d'Education physique, d'Hygiène et de Morale (1869-1935): La domination virile. In : LAURENT, Daniel (org.). Actes du Colloques du CESH, Sport et Art dans l'Histoire. Lorient: CESH, 2008. p. 29-40.

GLEYSE, Jacques. Making Angels. Bodily restraints championed in French school textbooks on moral values, 1880-1964. History of Education \& Children's Literature, [s.l.], v. IX, n. 1, p. 27-45, 2014.

GLEYSE, Jacques. A instrumentalização do corpo: uma arqueologia da racionalização instrumental do corpo, da Idade Clássica à Época Hipermoderna. Tradução de Avelino Aldo de Lima Neto, Cláudia Emília Aguiar Moraes e Fábio Luís Santos Teixeira. São Paulo: LiberArs, 2018.

GLEYSE, Jacques. O verbo e a carne: uma arqueologia do corpo nos manuais escolares franceses de moral e de higiene (1880-1974). Tradução de Avelino Aldo de Lima Neto, Bruno Medeiros Roldão de Araújo e Cláudia Emília Aguiar Moraes. São Paulo: LiberArs, 2020.

LAUNEY, H; LAUNEY, J.; RASCAL, L. Morale. Instruction civique - Droit privéEconomie politique, Enseignement primaire supérieur. Trois années réunies. Paris: Larousse, 1921.

MÉZIÉRES, Maurice-Auguste. Education morale et instruction civique à l'usage des Ecoles primaires. Cours moyen et supérieur. Paris: Delagrave, 1893.

MOSCONI, Nicole. La Mixité dans l'enseignement secondaire un faux-semblant. Paris: PUF, 1989.

NONUS; POIRE-CHOQUET. Résumés des leçons de morale et d'instruction civique. Amiens: Poiré-Choquet, 1890.

PAPE-CARPANTIER, Marie; DELON, Charles. Petites lectures morales. Premières notions de grammaire. Paris: Hachette, 1900.

PÉCAUT, Elie. Cours de morale et d'hygiène. Paris: Hachette, 1882.

PIERRE, Albert; LETRAIT, Léon; BODIN, Zélie. Lectures et récitations morales. Paris: Nathan, 1909. 
GLEYSE, J.; NETO, A. A. de L. Uma moral "corporal” generificada nos manuais escolares franceses...

PIZON, André. Hygiène, Garçons et filles. Lycées et collèges et Enseignement primaire supérieur. Paris: Doin, 1930.

POIGNET, André; BERNAT, Henri. Le livre unique de morale \& d'instruction civique. Paris: Auguste Godchaux, 1919.

SEIGNETTE, Adrien. Morale et enseignement civique. Cours supérieur. Paris: P. Dupont, 1895.

VILLARD, Gaston. Morale en action. Six à 10 ans. Paris: Nathan, 1964.

Texto recebido em 04/08/2020.

Texto aprovado em $25 / 11 / 2020$. 